\title{
Strategies of Controlling Vibriosis in Fish
}

\author{
Hasnazifa Huzmi ${ }^{1,2, *}$, Ina-Salwany M.Y ${ }^{1,2}$, Natrah F.M.I ${ }^{1,2}$, Fadhil Syukri ${ }^{1}$, Murni Karim ${ }^{1,2}$ \\ ${ }^{1}$ Department of Aquaculture, Faculty Agriculture. ${ }^{2}$ Institute of Bioscience \\ Universiti Putra Malaysia, 43400, Serdang, Selangor, Malaysia \\ ${ }^{1}$ Department of Aquaculture, Faculty Agriculture. ${ }^{2}$ Institute of Bioscience \\ Universiti Putra Malaysia, 43400, Serdang, Selangor, Malaysia \\ ${ }^{1}$ Department of Aquaculture, Faculty Agriculture. \\ Universiti Putra Malaysia, 43400, Serdang, Selangor, Malaysia \\ ${ }^{1}$ Department of Aquaculture, Faculty Agriculture. ${ }^{2}$ Institute of Bioscience \\ Universiti Putra Malaysia, 43400, Serdang, Selangor, Malaysia \\ ${ }^{*}$ Corresponding author's email: hasnazifahuzmi [AT] gmail.com
}

\begin{abstract}
The growth of the aquaculture industry is becoming more important in the food production sector. Presently, the biggest problem in aquaculture is bacterial diseases that infect the host thus causing outbreaks and economic losses. Vibriosis is a potentially lethal threat in commercial fish farming. Based on previous researches, various infections of the Vibrio genus have been reported hence their virulence is not fully understood. This review aims to provide enlightenment through research findings on Vibriosis-infected fish. Besides, some guidelines regarding control measures of Vibrio in aquaculture, such as the application of immunostimulant, antibiotics, probiotics and quorum sensing molecules, will be also reviewed.
\end{abstract}

Keywords- Fish, Vibriosis, control measures

\section{INTRODUCTION}

The aquaculture industry is one of the fastest growing food sectors and may offer opportunities even on a small scale. The reported global aquaculture production of food fish, including fin fishes, crustaceans, mollusks and other aquatic animals for human consumption, reached a staggering height of 79.3 million tons in 2016 representing a decreased of almost 2 million tones from the 81.2 million tones in 2015 (FAO, 2018). Globally, well-known cases of disease outbreaks are increasing in both occurrence and intensity in many marine taxa (Burge et al., 2014). However, mass production through intensive culture with high density condition has caused the outbreaks of diseases, especially by bacteria infection. Therefore, there are various culture practices that have been explored in order to increase the production and to reduce the mortalities in farms and hatcheries (Jasmin et al. 2016). The bacterial species, particularly Vibrio species, are often related to low survival rates in the hatchery. Vibrio species belongs to members of Gamma proteobacteria and Gram negative, usually motile rod (Thompson et al. 2004). These bacteria are described as luminescent Vibrios such as Vibrio harveyi, and closely related bacteria such as Vibrio campbelli and Vibrio parahaemolyticus (and not all strains are luminescent (Defoirdt et al. 2006). Infected fish by Vibrio sp. usually suffered from swollen spleen, abdominal dropsy, intestine inflammation, scale shedding, epidermal bleeding, pop-eye and fin and tail rot (Figure 1) (BioAqua Vietnam, 2013). At its most serious condition, the caudal peduncle was ulcerated up to the muscle. Vibrio alginolyticus is normally involved in epizootic occurrences in cultured orange-spotted grouper (Epinephelus coioides) in Chinese aquaculture, causing fish mortality and economic losses (Huang, 2005). Some of the Vibrio species are potentially zoonotic to humans, causing the risk of zoonosis in aquaculture professionals and consumers of aquaculture products (Austin, 2010). Aquaculture development mainly for infectious disease prevention alternatives strategies is urgently needed to minimize the risk of spreading microbial using environmentally friendly tools. Disease resistance depends on the interaction of host, pathogen and environment (Sniezko, 1970). To obtain more sustainable aquaculture industry, various disease control and prevention alternative strategies need to be taken including the use and application of non-chemical products, strict biosecurity measures and use of vaccines, probiotic, quorum sensing inhibitors and immunostimulant (Liu et al. 2003). Therefore, this paper discussed the urgent need in aquaculture development for microbial control strategies since disease outbreaks are 
recognized as important constraints to aquaculture and despite the fact that the development of antibiotic resistance has become a matter of growing concern.

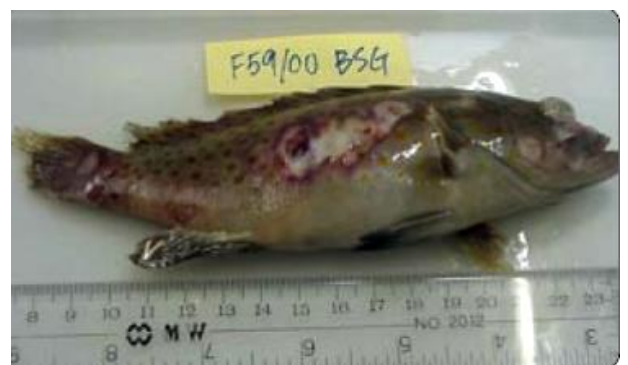

Figure 1: Typical ulcerative, popeye, fin and tail rot caused by Vibrio spp. in grouper (BioAqua Vietnam, 2013).

\section{VIBRIOSIS IN FISH}

The current growth in aquaculture production is influenced by the rising number of disease outbreaks, which affect the production, profitability, and stability of the industry worldwide. Vibriosis is the most common and dangerous pathogen in marine fish aquaculture worldwide. Recently, Vibrio has gained attention because several species are related to human diseases (Amaro and Biosca, 1996), and it has also caused multibillion dollar of losses and severe mortality of livestock in many countries. Based on some laboratory-based experiments, Vibrio sp. are pathogenic not only to saltwater fish, but also to brackish water fish, with mortalities up to $100 \%$ (Austin and Austin, 2007). Vibriosis is caused by several Vibrios: $V$. harveyi, V. parahaemolyticus, V. alginolyticus, V. anguillarum, and V.vulnificus. Vibrio harveyi causes serious vibriosis, resulting in massive grouper fish death and impoverish economic losses (Harikrishnan et al. 2011).

Common foodborne diarrheal diseases are caused by eating raw seafood infected by $V$. parahaemolyticus (Wang et al., 2011) and the poisoning occurred again regarding $50 \%$ outbreaks caused by Vibrio (Gao et al., 2012). Presently, there are alternatives to control vibriosis in aquaculture including a few allowable antibiotics. Animals infected by shows signs of lethargy, appendage and tissue necrosis, slow growth, body malformation, bioluminescent, muscle opacity, slow metamorphosis and melanization (Aguirre-Guzman et al., 2004). The spreading of vibriosis occurrence from adhesion to colonization within the host could be the key to formulate therapeutic strategies for disease prevention and treatment. To reduce losses caused by vibriosis infection to a minimum, several attenuated Vibrio sp. strains derived from wide-type have been constructed by recombinant DNA technology, which states a full range of protecting antigens without causing infection in the host and provides efficient protection against vibriosis.

\subsection{Virulence mechanism of vibriosis}

The most current work on Vibrio diseases of marine fish has agreed to the explanation of virulence mechanisms. The virulence factors of $V$. harveyi have been reported and identified over the years. The highlight of several studies suggests that Vibrio may be considered as highly virulent fish pathogen with three major infectious cycles, namely: (i) entry of antibody, (ii) formation and amplification, through avoiding host resistance and causing destruction to host tissues and cells and (iii) exit (Austin et al., 2007). These processes affected the host, resulting in motility, adhesion, gross tissue damage, iron overload and innate host defense (Donnenberg, 2000). The susceptibility of moribund grouper (Epinephelus coioides) to Vibrio carchariae infection have been interpreted by Yii et al. (1997), who demonstrated that the $\mathrm{LD}_{50}$ value was $2.53 \times 10^{7}$ colony structure units/grouper body weight.

This particular strain $V$. carchariae has been confirmed to be susceptible to chloramphenicol, oxolinic acid, oxytetracycline, doxycycline-HCl, nalidixic acid and sulfonamide, as opposed to ampicillin and penicillin G. In another study by Saeed (1995), the $\mathrm{LD}_{50}$ value was high in brown-spotted grouper (Epinephelus tauvina): $1.56 \pm 0.19 \times 10^{9} \mathrm{CFU} / \mathrm{ml}$ for intramuscularly (IM) infection and $1.59 \pm 0.17 \times 10^{9} \mathrm{CFU} / \mathrm{ml}$ for intraperitoneal (IP) infection; thus showing that $V$. harveyi should be considered as a potential infection. Similarly, $V$. carchariae strains from brown-spotted grouper appeared to be more virulent to moribund grouper (Lee et al., 2002). However, the extracellular products (ECPs) of $V$. harveyi have been confirmed to consist of hemolysins and several proteases and other hydrolytic enzymes (Zhang et al.2005). Gelatinase, lipase, phospholipase, siderophores, cysteine protease, metalloprotease, and hemolysins are the key ECPs that have been identified (Liu et al. 1999). Protease and antagonism of the extracellular products of $V$. carchariae the pathogenesis agents of gastroenteritis in E. coioides were studied and the role of protease has been considered as the cause for gastroenteritis in the grouper (Lee et al. 1999). Certain vaccines often contain some potential risks in virulence recovery and spread infections; therefore new approaches are greatly needed to improve the biological safety of fishes. 


\section{STRATEGIES IN FISH HEALTH MANAGEMENT: PREVENTION AND CONTROL}

\subsection{Antibiotics}

Disease resistance depended heavily on the interaction of host, pathogen, and environment (Sniezko, 1970). To manage vibriosis infection in aquaculture, fish may be fed with antibiotic medicated food (Pridgeon et al. 2012). The use of antibiotics was widely accepted in the beginning which able to reduce diseases thus, it leads to the emergence of numerous antibiotic-resistant bacteria (Shazwani et al. 2015). In order to promote the development of antibiotic-resistant bacteria in fish and the environment, lactic acid bacteria was introduced (Shazwani et al. 2015). Many treatment methods involving the use of antibiotic have been adapted in aquaculture to reduce vibriosis. Common antibiotics applied in aquaculture are amoxicillin, benzylpenicillin, co-trimazine, entrofloxacin, florfenicol, flumequine, oxolinic acid, oxytetracycline, sarafloxacin, trimethoprim and sulphadiazine (Roque et al., 2001). The introduction of oxytetracycline in food successfully decreased mortality amongst brown-spotted grouper from which $V$. harveyi was isolated in large amounts and practically pure forms (Saeed, 1995). However, antibiotics used in aquaculture industry product has caused problem worldwide. It may cause an altered human gut microflora which can further lead to allergy reactions and toxicity (Cabello, 2006). It is widely known that the application of veterinary medicines and chemical additives, especially antibiotics, may be hazardous to public health by promoting growth and reproduction, and strengthening the resistance in bacterial strain. As a result, 2,400 export consignments of Vietnamese fishery products have been rejected by the United States authority, while 422 shipments have been rejected by EU authorities between the year 2002 to 2010 (East Asia, 2013).

\subsection{Immunostimulation}

The word 'immunostimulant' refers to any chemical compound that activates white blood cells (leukocytes) which may render the animals more resistant to infection by harmful microorganisms in aquaculture, such as viruses, bacteria, fungi and parasites (Raa, 2000). The use of immunostimulants showed increase resistance of aquatic organisms against infectious disease. A previous study reported that grouper (Epinephelus fuscoguttatus) fed with diet introduced with sodium alginate or k-carrageenan has shown an increased in resistance and innate immune response against $V$. alginolyticus (Cheng et al., 2008). Several studies have also experimented dietary supplements infused with Phellinus linteus for grouper Epinephelus bruneus, which was later tested with V. anguillarum, V. harveyi, V. alginolyticus, and $V$. carchariae. The results indicated that Phellinus linteus enriched-diet had heightened cellular and humoral immunity response and the grouper was thus protected against vibriosis. Phagocytes such as neutrophils and macrophages play an important role in the anti-bacterial resistance, in which these cells consume and kill bacteria during the production of reactive oxygen species (ROS), including superoxide anion, hydrogen peroxide and hydroxyl radicals in the respiratory burst (Ellis et al., 1999). In tilapia (Oreochromis niloticus), a two week feeding of Lactobacillus rhamnosus significantly activated phagocytosis (Pirarat et al., 2006).

A number of probiotics can effectively modulate the production of pro-inflammatory cytokines, such as interleukin1 (IL-1), IL-6, IL-12, tumor necrosis factor a (TNF-a) and interferon-gamma (IFN-g) and anti-inflammatory cytokines, such as IL-10 and transforming growth factor b (TGF b) in many organisms (Niers et al., 2005). Thus, a large number of microorganisms have been considered for use as probiotics in aquaculture with a mechanism of action involving more immunoprotective, wherein some of subcellular components act as immunostimulating agents in their own right. Respiratory outbreak activity is also an important natural protection mechanism of fish. Case studies on probiotics have shown that it improves respiratory burst of phagocytic cells, which play a role in the protection of non-specific cell (Panigrahi et al., 2004). The two-week feeding lactic acid bacteria significantly enhanced the respiratory burst of secondary blood lymphocytes from both fish and strain demonstrating effective protection of Cobia (Rachycentron canadum) against photobacteriosis challenge (RPS 1/4 74.3) (Xing et al., 2013). On the other hand, lysozyme is a factor of the innate immune system and plays a main role in the resistance mechanism because of its anti-cancer, anti-viral and opsonization properties (Jolles et al., 1984). It is noted that the addition of L. rhamnosus $\left(10^{9} \mathrm{CFU} \mathrm{g}^{-1}\right)$ as feed additives for 30 days improved lysozyme activity in rainbow trout (Panigrahi et al., 2004). The peroxidase is an important enzyme that uses the oxidizing extreme to create hypochlorous acid to kill pathogens (Akhter et al., 2015) while cytokines contain chemokines, interferons, interleukins, lymphokines, tumor necrosis factor (Oxford University Press., 2010).

\subsection{Probiotic}

Another trending method is the use of probiotic immunostimulants (Chatterjee et al.2012), where probiotics is used to control disease in aquaculture. Furthermore, the efficiency of probiotics introduced in the diet can increase fish's absorption of nutrients. It is also well-known to stimulate reproduction and increase stress tolerance in aquaculture species. According to Karim et al. (2013) and Ina-Salwany et al. (2015), probiotics in aquaculture have been suggested 
to have several modes of action which included improved water quality, improved immune responses of host species, improved nutrition of host species through the production of additional digestive enzymes, competition for space with pathogenic bacteria and the production of antimicrobial compounds. Probiotic products are gaining worldwide acceptance in fighting against various bacterial species (Bacillus sp., Lactobacillus sp., Enterococcus sp., Saccharomyces cerevisiae and Carnobacterium sp.) and their use is monitored via management guidance (Cruz et al. 2012). The major concern towards the application of probiotics is that in some cases they are unable to preserve themselves and consequently has to be added regularly and at high awareness (Vine et al. 2006). Table 1 summarizes that many probiotic bacteria are applied to prevent and control main diseases in fish. According to Huang et al. (2014), the potency of lactic acid bacterium Pediococcus pentosaceus as a probiotic for the orange-spotted grouper through feeding is probable, thus protecting the grouper against vibriosis. Aside from that, probiotics as a source of micro- and macronutrients also reduces the expression of virulence genes or interrupt quorum sensing mechanism, by which in turn, increase the contribution of enzymatic digestion system (Merrifield et al. 2010). The use of probiotics is considered as a potential alternative to the use of some chemicals.

In addition, there are two types of aquatic probiotics, 1) gut probiotics which can be mix together with feed and 2) water probiotics which can multiply in the water medium and eliminate the pathogenic bacteria by consuming all present nutrients. Probiotics works as antagonistic against pathogens, disease resistance, improving enzyme activity, improvement of the immune response and feed digestibility and fish health performance. The typical element of a probiotic microbe is that it should be able to colonize the gastrointestinal tract, but the intestinal microflora in aquatic animals' changes rapidly with the continuous flood of microbes coming from water and food. It is considered so far as the best solution to avoid colonization of the gut by other disease-causing bacteria through a process known as competitive elimination. Although the addition of potentially probiotic bacteria to culture water in larval fish systems is a means of biocontrol, it is possible that some bacteria may possibly be ingested, subsequently producing several probiotic effects on the host animal. Since fish larvae are known to have high inter-individual unpredictability, it makes the efficiency of potential treatment challenging (Meyer et al., 2012).

To optimize the conditions for the species being farmed, intensive aquaculture should be carefully controlled. A new definition of probiotics, also applicable to aquatic environments, is proposed, and a detailed report is agreed upon on their possible modes of action, i.e., production of compounds that are inhibitory toward pathogens, competition with harmful bacteria for nutrients and energy, antagonism with harmful species for adhesion sites, enhancement of the immune response of the animal, improvement of water quality, and interaction with phytoplankton. Therefore, the application of probiotics has been shown the potential alternative to the use of antibiotics in animal production (Pandiyan et al., 2013). There is an urgent need in aquaculture development for microbial control strategies since disease outbreaks are recognized as important limitations to aquaculture and in spite of the fact that the development of antibiotic resistance has become a matter of growing concern. 
Table 1.Probiotic bacteria challenge in various species of Grouper Epinephelus sp..

\begin{tabular}{|c|c|c|c|}
\hline Potential probiotic & Disease & Probiotic efficiency & References \\
\hline Bacillus \&Micrococcus & Vibrio alginolyticus & $\begin{array}{l}\text { Play a role in inhibiting the pathogen by production of extracellular enzyme and improve the feed } \\
\text { digestion. }\end{array}$ & Nora et al.2016 \\
\hline Bacillus & Vibrio alginolyticus & $\begin{array}{l}\text { Potential probiotics for disease prevention and improving the productivity of tiger grouper } \\
\text { Epinephelus fuscoguttatus larvae and juveniles. }\end{array}$ & Yasin et al. 2016 \\
\hline Pediococcuspentosaceus & Vibrio anguillarum & $\begin{array}{l}\text { Enhance innate immunity, psychological health and resistance to vibrio anguillarumin orange- } \\
\text { spotted grouper(Epinephelus coioides). }\end{array}$ & Jian-Bin et al. 2014 \\
\hline Bacillus subtilis & Streptococcus sp. & $\begin{array}{l}\text { Improve the growth performance, immune response and disease resistance of the grouper, } \\
\text { Epinephelus coioides. }\end{array}$ & Liu et al. 2012 \\
\hline $\begin{array}{l}\text { Bacilluscereus } \\
\text { \&Micrococcus luteus }\end{array}$ & $\begin{array}{c}\text { Vibrio alginolyticus, Vibrio } \\
\text { parahaemolyticus, } \\
\text { Vibrio harveyi andAeromonas } \\
\text { hydrophila }\end{array}$ & $\begin{array}{l}\text { Inhibit pathogens and their sensitive and intermediate susceptibility to all the antibiotics tested } \\
\text { cannot be neglected. }\end{array}$ & Nurhidayu et al. 2012 \\
\hline Psychrobactersp & Staphylococcus saprophyticus & $\begin{array}{l}\text { Improved the autochthonous microbial diversity along the gastrointestinal tract of grouper } \\
\text { Epinephelus coioides. }\end{array}$ & Hong-Ling et al. 2011 \\
\hline Saccharomyces cerevisiae & Streptococcussp. & $\begin{array}{l}\text { Enhanced the growth, innate immune responses, and disease resistance of the grouper, } \\
\text { Epinephelus coioides. }\end{array}$ & Chiu et al. 2010 \\
\hline $\begin{array}{l}\text { Bacillus pumilus \&Bacillus } \\
\text { clausii }\end{array}$ & Vibrio sp. & Reduction of Vibrio levels. & Yun-Zhang et al. 2013 \\
\hline $\begin{array}{l}\text { Bacillus clausii, } \\
\text { Bacillus pumilus \& } \\
\text { Psychrobacter sp. }\end{array}$ & $\begin{array}{l}\text { Streptococcus iniae, Streptococcus } \\
\text { parauberis }\end{array}$ & Improved the growth performance and immune responses of grouper Epinephelus coioides. & Yun-Zhang et al.2010 \\
\hline Lactobacillus plantarum & Streptococcus sp, Iridovirus & Enhanced the growth, innate immune responses, and disease resistance. & Voet al. 2009 \\
\hline
\end{tabular}




\section{Lactobacillusplantarum}

Paenibacillus polymyxa

Paenibacillus polymyxa

Bacillus amyloliquefaciens

Bacillus subtilis

Bacillus subtilis and

Lactobacillus acidophilus,
Vibrio anguillarum

Pseudomonas fluorescens, Pseudomonas aeruginosa, Aeromonas

sobria, Aeromonas hydrophila,

Aeromonas caviae, Bacillus subtilis

Aeromonas hydrophila

Vibrio spp.

Aeromonas hydrophila,

Streptococcus iniae
Induced inflammation and apoptosis in silvery pomfret (Pampus argenteus) intestinal epithelial

cells

Antibacterial activity and probiotic characterization of autochthonous Paenibacillus polymyxa isolated from Anabas testudineus (Bloch, 1792)

Evaluation of in vivo probiotic efficiency of Bacillus amyloliquefaciens in Labeo rohita challenged by pathogenic strain of Aeromonas hydrophila MTCC 1739.

Control of pathogenic Vibrio spp. by Bacillus subtilis BT23, a possible probiotic treatment for black tiger shrimp Penaeus monodo.

Studies on Bacillus subtilis and Lactobacillus acidophilus, as potential probiotics, on the immune response and resistance of Tilapia nilotica(Oreochromis niloticus) to challenge
Gao etal., 2016

Midhun et al., 2017

\section{Nandi etal., 2018}

Vaseeharan et al., 2003

Aly et al., 2008 Infections. 


\subsection{Qourum Sensing}

Quorum sensing (QS) is defined as the mechanism which allows bacteria to coordinates the expression of certain genes in response to the presence of small signal molecules (Noorashikin et al. 2016). Quorum sensing regulates gene by detecting and responding to cell regulation density. It is one of the new alternatives to control the bacterial infection caused by Vibrio spp. by disrupting bacterial cell-to-cell communications. The effect of halogenated furanones had been reported to interrupt acyl homoserine lactone (AHL) and caused an intermediated signaling in Gram-negative bacteria (Hentzer et al.2003). More interestingly, quorum sensing interrupting compounds can inhibit the growth of the vibrios. The antipathogenic compounds tend to create a selective pressure for the increase of resistance making this method highly recommendable as an efficient biocontrol strategy. Therefore, it would be valuable to try to generate novel quorum sensing disrupting compounds, such as furanone analogues for instance could be applied to manage luminescent vibriosis in aquaculture. Pathogens that can break down AHL-type indicator molecules have been published widely in the literature (Uroz et al.2003). Quorum sensing is used to investigate the inhibition property of probiotics to other bacterial communities. To examine the management of potential probiotic ability, the Fluorescent in situ Hybridization (FISH technique is used as a potential tool to characterize its dynamics and efficiency in the control of pathogenic bacteria (Del'duca et al. 2013). Lamari et al. (2013) suggest that the estimate of probiotics should take into account ontogenetic chronology for improving larval quality. Some researchers (Yasin et al., 2016) have proved that the use of selected probiotics can be an alternative method for the protection of aquatic animals against diseases. As a result, further work on the effects of treatment is required if the onset has already occurred.

\subsection{Vaccines}

At the wake of vaccination as a new trend in bacterial disease prevention and pathogen control in aquaculture, new vaccines have been developed to control vibriosis in fish (Chuang et al.2014). Injection remains to be the most popular method in fish vaccination - mainly due to the possibility of an exact dose of vaccine which could bring the best effect when inserted (Marlowe et al. 2014). There are numerous elements that have been used as vaccines against infection caused by vibriosis. It needs to be easy to use (immersion or oral delivery workable) and offer a broader and longer protection. Such advantages are urgently sought by the aquaculture industry in order to solve the problems in the management of vaccines in fish. Understanding of the immune mechanisms of the species of fish during vaccination will lead to higher quality vaccine design and formulation when bacterial infections occur in the aquaculture facility. According to Zafran et al. (2016), polyvalent vaccine has been administered through immersion had been shown to the immune response of juvenile tiger grouper Epinephelus fuscoguttatus against disease in floating net cages. On the other hand, diet enriched with mushroom (Phellinus linteus) extract increase the growth, immune response and disease resistance of kelp grouper, E. bruneus against vibriosis (Harikrishnan et al. 2011). In addition, ultrasound treatment was administered on juvenile groupers, Epinephelu sawoara to facilitate the vaccination against vibriosis (Huang et al.2002). Outer membrane proteins (OMPs) have become the focus for vaccine development nowadays which due to the exposed epitopes on the bacteria cell surface and its conserved nature (Nehlah et al. 2017). OmpK and OmpW are the good candidates of potential proteins for vaccine development. It is reported that OmpK is widely distributed among Vibrio sp. and acted as an immunogenic antigen against vibriosis while OmpW is a major antigen in bacterial infections and also highly immunogenic (Nehlah et al. 2017).

\section{CONCLUSIONS}

It is certain that the use of probiotics is able to enhance immunity to increase aquaculture sustainability. The rising economic loss affected by fish infections showed the need to develop new preventative strategies. Some of the useful methods in fish health management skills have only been tested in the laboratory, whereas other methods that have a longer history have been tested through farm experiments. Viral, bacterial, and parasitic diseases rise to be the major concern that poses threat towards aquaculture in the Asia Pacific region. A sensible approach of biocontrol management is expected to be valuable. Each of the currently available method has its benefits but there are also limitations, therefore it is advisable to cover them altogether with random screening to maximize protection.

\section{SIGNIFICANCE STATEMENT}

This review explained the solutions in managing vibriosis disease in fish. This study will help the researchers to gain more knowledge and able to explore more about vibriosis disease as well as the techniques on the prevention. Indirectly, this study can be beneficial for the aquaculture industries on providing information on the strategies to combat vibriosis in order to produce high and quality production.

\section{ACKNOWLEDGEMENT}


This research was supported by Ministry of Higher Education Malaysia (MOHE) through SATREPS JICA-JST COSMOS 2016-2021, Higher Institution Centre of Excellence (HiCoE) grant of Innovative Vaccine and Therapeutics against Fish Diseases, Vote No: 6369100 and Universiti Putra Malaysia under High Performance Individual Research Grants UPM/700-2/1/GPB/2017/9553100.

\section{REFERENCES}

1. Aly,S.M., Abdel-Galil Ahmed,Y., Abdel-Aziz Ghareeb, A., and Mohamed,M.F., 2008. Studies on Bacillus subtilis and Lactobacillus acidophilus, as potential probiotics, on the immune response and resistance of Tilapia nilotica (Oreochromis niloticus) to challenge infections, Fish Shell. Immunol., 25: 128-136.

2. Angeles Esteban, M., 2012. An overview of the immunological defenses in fish skin, ISRN Immunol. Pp 1-29.

3. Aguirre-Guzmán, G., H.M. Ruiz, and F. Asxencio. 2004. A review of extracellular virulence product of Vibrio species important in disease of cultivated shrimp. Aquaculture Res., 35: 1395-1404.

4. Anon, 2017. Center for Disease Control and Prevention. Vibrio cholerae infection. https://www.cdc.gov/cholera/general/; 2017.

5. Biering, E., Vaagnes, O., Krossoy, B., Gulla, S., and Colquhoun, D.J., 2016. Challenge models for atypical Aeromonas salmonicida and Vibrio anguillarum in farmed Ballan wrasse (Labrus bergylta) and preliminary testing of a trial vaccine against atypical Aeromonas salmonicida. J. Fish Dis., 39: 1257-1261.

6. Burge, C.A., Mark, E. C., Friedman, C.S., Froelich, B., Hershberger, P.K., Hofmann, E.E., Petes, L.E., Prager, K.C., Weil, E., Willis, B.L., Ford, S.E., and Harvell, C.D., 2014. Climate change influences on marine infectious diseases: implications for management and society. Annual Review of Marine Science, 6: 249-277

7. Cai, S.H., Lu, Y.S., Jian, J.C., Wang, B., Huang, Y.C., Tang, J.F., Ding, Y., Wu, Z.H., 2013. Protection against Vibrio alginolyticus in crimson snapper Lutjanus erythropterus immunized with a DNA vaccine containing the ompW gene. Dis. Aquat. Organ., 106: 39-47.

8. Cano-Gómez, A., Goulden, E.F., and Owens, L., 2010. Vibrio owensii sp. nov., isolated from cultured crustaceans in Australia. FEMS Microbiol Lett., 302: 175-81.

9. Charles, R.C., and Ryan, E.T., 2011. Cholera in the 21st century. Curr. Opin Infect., 24: 472-477.

10. Cardenas,T,R., Angulo, C., Hori,O.S., Velazquez,L.E.,and Reyes, M., 2016. Becerril, B-cell activating CpG ODN 1668 enhance the immune response of Pacific red snapper (Lutjanus peru) exposed to Vibrio parahaemolitycus, Dev. Comp. Immunol., 62: 72- 81.

11. Chu, C.Y., Liu, C.H., Liou,J.J., Lee,J.W., and Cheng, L.W., 2015. Development of a subunit vaccine containing recombinant Riemerella anatipestifer outer membrane protein A and CpG ODN adjuvant, Vaccine. 33: 92-99.

12. Darshanee Ruwandeepika, H.A., Sanjeewa Prasad Jayaweera, T., Paban Bhowmick, P., 2012. Pathogenesis, virulence factors and virulence regulation of Vibrios belonging to the Harveyi clade. Rev Aquac., 4:59-74.

13. FAO, 2018. The State of World Fisheries and Aquaculture 2018 - Meeting the sustainable development goals. Rome.

14. Gao, M., Zhang, Z., and Ling, Y., 2012. Epidemiological characteristics of collective food poisoning caused by Vibrio parahaemolyticus in a city during recent decade. Chin. J. Sch. Dr., 26: 824-826.

15. Gomez-Gil, B., Soto-Rodríguez, S., and García-Gasca, A., 2004. Molecular identification of Vibrio harveyi-related isolates associated with diseased aquatic organisms. Microbiology, 150: 1769-77.

16. Ina-Salwany, M.Y., Hishammuddin, H., Zulperi, Z., Salema, M., Karim, M., and Natrah, F.M.I., 2015. Elucidating the probiotic potential of Malaysian Paenibacillus pabuli against Vibrio alginolyticus in Artemia culture. Asian Journal of Agricultural Research, 9: 223-236, DOI: 10.3923/ajar.2015.223.236

17. Jasmin, M.Y., Wagaman, H., Tan, A.Y., Ina-Salwany, M.Y., Daud, H.M., and Karim, M., 2016. Screening and evaluation of local bacteria isolated from shellfish as potential probiotics against pathogenic Vibrios. Journal of Environmental Biology, 37: 801-809.

18. Karim, M., Zhao, W., Rowley, D., Nelson, D., and Gomez-Chiarri, M., 2013. Probiotic strains for shellfish aquaculture: Protection of eastern oyster, Crassostrea virginica, larvae and juveniles against bacterial challenge. Journal of Shellfish Research, 32: 401-408, DOI: http://dx.doi.org/10.2983/035.032.0220

19. Labreuche, Y., Pallandre, L., Ansquer, D., Herlin, J., Wapotro, B., and Le Roux, F., 2012. Pathotyping of Vibrio isolates by multiplex PCR reveals a risk of virulent strain spreading in new Caledonian shrimp farms. Microb. Ecol., 63: $127-138$.

20. Midhun, J., Sahadevan, N., Vysakh, A., Damodaran, A., Radhakrishnan, K., and Jyothis,M., 2017. Antibacterial activity and probiotic characterization of autochthonous Paenibacillus polymyxa isolated from Anabas testudineus (Bloch, 1792). Microbial Pathogenesis, 113: 403-411

21. Nandi,A., Banerjee,G., Dan,S.K., Ghosh,K., and Ray,A.K., 2017. Evaluation of in vivo probiotic efficiency of Bacillus amyloliquefaciens in Labeo rohita challenged by pathogenic strain of Aeromonas hydrophila MTCC 1739, Probiotics Antimicrob. Proteins. Pp 1-8 
22. Nandi, A. Banerjee, G., Dan S.K., and Ray, A.K., 2018. Evaluation of In Vivo Probiotic Efficiency of Bacillus amyloliquefaciens in Labeo rohita Challenged by Pathogenic Strain of Aeromonas hydrophila MTCC 1739. Probiotics Antimicrob Proteins,. 10: 391-398.

23. Ina-Salwany, M.Y., Hishammuddin, H., Zulperi, Z., Salema, M., Karim, M., and Natrah, F.M.I., 2015. Elucidating the probiotic potential of Malaysian Paenibacillus pabuli against Vibrio alginolyticus in Artemia culture. Asian Journal of Agricultural Research, 9: 223-236, DOI: 10.3923/ajar.2015.223.236

24. Jasmin, M.Y., Wagaman, H., Tan, A.Y., Ina-Salwany, M.Y., Daud, H.M., and Karim, M., 2016. Screening and evaluation of local bacteria isolated from shellfish as potential probiotics against pathogenic Vibrios. Journal of Environmental Biology, 37: 801-809.

25. Karim, M., Zhao, W., Rowley, D., Nelson, D., and Gomez-Chiarri, M., 2013. Probiotic strains for shellfish aquaculture: Protection of eastern oyster, Crassostrea virginica, larvae and juveniles against bacterial challenge. Journal of Shellfish Research, 32: 401-408, DOI: http://dx.doi.org/10.2983/035.032.0220

26. Peng, W., Shi, Y., Li, G.F., He, L.G., Liang, Y.S., Zhang, Y., Zhou, L.B., Lin, H.R., Lu, D.Q., 2016. Tetraodon nigroviridis: a model of Vibrio parahaemolyticus infection. Fish. Shellfish. Immunol., 56: 388-396.

27. Quanxin, G., Qian, G., Minghua, M., Chenjie, Z., Shiming, P. and Zhaohong, S., 2016. Ability of Lactobacillus plantarum lipoteichoic acid to inhibit Vibrio anguillarum-induced inflammation and apoptosis in silvery pomfret (Pampus argenteus) intestinal epithelial cells. Fish \& Shellfish Immunology, 54: 573-579.

28. Reyes-Becerril,M., Maldonado,G.M., Guluarte,C., Leon,G.A., Rosales, M.S., Ascencio,F., Hirono,I., Angulo,C., 2016. Evaluation of ToxA and Vibrio parahaemolyticus lysate on humoral immune response and immune-related genes in Pacific red snapper. Fish. Shellfish Immunol., 56: 310-321.

29. Rico, A., Dimitrov, M.R., Van Wijngaarden, R.P.A., Satapornvanit, K., Smidt, H., and Van den Brink, P.J., 2014. Effects of the antibiotic enrofloxacin on the ecology of tropical eutrophic freshwater microcosms. Aquat. Toxicol., 147: 92-104.

30. Silva, A.J.D., Zangirolami,T.C., Novo-Mansur,M.T.M., Giordano,R.D.C., Martins,E.A.L., 2014. Live bacterial vaccine vectors: an overview, Braz. J. Microbiol., 45: 1117-1129.

31. Turner, J.W., Paranjpye, R.N., Landis, E.D., Biryukov, S.V., González-Escalona, N., Nilsson, W.B., Strom, M.S., 2013. Population structure of clinical and environmental Vibrio parahaemolyticus from the Pacific Northwest coast of the United States. PLoS One. 8: 55726.

32. Vaseeharan, B., and Ramasamy, P., 2003. Control of pathogenic Vibrio spp. by Bacillus subtilis BT23, a possible probiotic treatment for black tiger shrimp Penaeus monodon. Lett Appl Microbiol., 36: 83-87.

33. Wang, F., Jiang, L., Yang, Q., Han, F., Chen, S., Pu, S., Vance, A., and Ge, B., 2011. Prevalence and antimicrobial susceptibility of major food borne pathogens in imported seafood. J. Food Prot., 74: 1451-1461.

34. Wang, H. P., Zhang, J. L., Jiang, T., Bao, Y. X., and Zhou, X. M., 2011. Insufficiency of the Kanagawa hemolytic test for detecting pathogenic Vibrio parahaemolyticus in Shanghai, China. Diagn. Microbiol. Infect. Dis., 69: 7-11.

35. Wang, H., Shen, F., Xiao, R., Zhou, Y., Dai, Y., 2013. Purification and characterization of antifungal compounds from Bacillus coagulans TQ33 isolated from skimmed milk powder. Ann. Microbiol., 63: 1075-1081.

36. Wu, Y., Wen, J., Ma, Y., Ma, X., and Chen, Y., 2014. Epidemiology of foodborne disease outbreaks caused by Vibrio parahaemolyticus, China, 2003-2008. Food Control, 46 :197-202.

37. Yang, Q., Defoirdt, T., 2015. Quorum sensing positively regulates flagella motility in pathogenic Vibrio harveyi. Environ. Microbiol., 17: 960-968.

38. Yasin, I. S. M., Razak, N. F., Natrah, F. M. I., \& Harmin, S. A., 2016. Selection and evaluation of Malaysian Bacillus spp. strains as potential probiotics in cultured tiger grouper (Epinephelus fuscoguttatus). Journal of Environmental Biology, 37: 791-800.

39. Ye, R., Xu, H., Wan, C., Peng, S., Wang, L., Xu, H., Aguilar, Z.P., Xiong, Y., Zeng, Z., Wei, H., 2013. Antibacterial activity and mechanism of action of epsilon-poly-L-lysine. Biochem. Biophys. Res. Commun., 439: $148-153$.

40. Zhang, D., Pridgeon,J.w., and Klesius,P.H., 2014. Vaccination of channel catfish with extracellular products of Aeromonas hydrophila provides protection against infection by the pathogen, Fish. Shellfish Immunol., 36: $270-275$.

41. Zhou, Z., Pang, H., Ding, Y., Cai, J., Huang, Y., Jian, J., Wu, Z., 2013. VscO, a putative T3SS chaperone escort of Vibrio alginolyticus, contributes to virulence in fish and is a target for vaccine development. Fish Shellfish Immun., 35: 1523-1531. 